\title{
Polimorfismo GSTM1 e GSTT1 no Câncer de Tireoide: Revisão Sistemática e Meta-análise
}

\author{
Lucas Cândido Gonçalves'; Bárbara Custódio Rodrigues da Silva²; Joaquim Ferreira Fernandes²; \\ Talita Ferreira Duarte ${ }^{3}$; Thainá Ferreira Silva ${ }^{4}$; Aline Ferreira da Silva Santos ${ }^{5}$; Larissa de \\ Oliveira Rosa Marquest; Antonio Márcio Teodoro Cordeiro Silva² \\ $\triangle$ joaquim0720@hotmail.com
}

1. Faculdade Única, Coronel Fabriciano - MG.

2. Universidade Católica de Goiás, Goiânia - GO.

3. Faculdade Unida de Campinas, Goiânia - GO

4. Universidade Federal de Goiás, Goiânia - GO.

5. Universidade Paulista, Goiânia - GO.

Histórico do Artigo: 0 autor detém os direitos autorais deste artigo.

Recebido em: 12 de novembro de $2020 \quad$ Aceito em: 19 de abril de $2021 \quad$ Publicado em: 31 de agosto de 2021

Resumo: Os cânceres de tireoide são doenças multifatoriais, derivadas do epitélio folicular e de células C parafoliculares. A deleção dos genes das glutationas-S-transferase, theta (GSTTI) e mu (GSTMI), pode reduzir a capacidade das células em desintoxicar agentes carcinogênicos. Verificar se há associação entre a presença ou ausência dos polimorfismos GSTT1 e GSTMl e os cânceres da tireoide. Trata-se de revisão sistemática e metaanálise, com seleção de artigos científicos nas bases de dados: PubMed, SciELO, ScienceDirect e LILACS. Os dados de 15 artigos foram extraídos e os testes estatísticos, considerando limite de significância de 5\%, foram realizados com 0 auxílio do software STATA ${ }^{\circledR}$ 16.0. A ausência do polimorfismo GSTMI apontou associação com 0 desenvolvimento dos cânceres da tireoide sem segregação por tipos (0R=1,15; IC95\%=1,01-1,32). No entanto, a presença dos polimorfismos GSTT1 e GSTMI não apresentaram associação, quando os cânceres da tireoide foram estratificados por tipos (papilar, folicular e papilar + folicular). A deleção de GSTMl e GSTT1 reduz a defesa frente agentes carcinogênicos. No entanto, os resultados da presente pesquisa apontaram ausência de associação entre a presença dos polimorfismos GSTTle GSTMle a ocorrência dos tipos de câncer da tireoide. Por outro lado, a ausência da GSTMI apresentou associação com os cânceres da tireoide, quando não estratificados por tipos.

Palavras-chave: Polimorfismo Genético, Neoplasias da Glândula Tireoide, Glutationa Transferase, Estresse Oxidativo.

\section{GSTM1 and GSTT1 Polymorphism in Thyroid Cancer: Systematic Review and Meta- analysis}

\begin{abstract}
Thyroid cancers are multifactorial diseases, derived from the follicular epithelium and parafolicular cells. Deletion of the genes for glutathione-S-transferase, theta (GSTTI) and mu (GSTMI) may reduce the cells' ability to detoxify carcinogenic agents. Check whether there is an association between the presence or absence of GSTT1 and GSTMl polymorphisms and thyroid cancers. This is a systematic review and meta-analysis, with selection of scientific articles in the databases: PubMed, SciELO, ScienceDirect and LILACS. The data from 15 articles were extracted and the statistical tests, considering a significance limit of $5 \%$, were performed with the aid of the STATA ${ }^{\circledR} 16.0$ software. The absence of the GSTMI polymorphism pointed to an association with the development of thyroid cancers without segregation by type $(0 \mathrm{R}=1.15 ; 95 \% \mathrm{CI}=1.01-1.32)$. However, the presence of GSTT1 and GSTM1 polymorphisms was not associated when thyroid cancers were stratified by types (papillary, follicular and papillary + follicular). The deletion of GSTMI and GSTTIreduces the defense against carcinogenic agents. However, the results of the present study pointed to the absence of an association between the presence of the GSTTl and GSTMl polymorphisms and the occurrence of types of thyroid cancer. On the other hand, the absence of GSTMl was associated with thyroid cancers, when not stratified by types.
\end{abstract}

Keywords: Polymorphism Genetic, Thyroid Neoplasms, Glutathione Transferase, 0xidative Stress. 


\title{
Polimorfismo GSTMl y GSTT1 en el Cáncer de Tiroides: Revisión Sistemática y Metanálisis
}

\begin{abstract}
Resumen: Los cánceres de tiroides son enfermedades multifactoriales, derivadas del epitelio folicular y las células parafoliculares. La eliminación de los genes de la glutatión-S-transferasa, theta (GSTTh) y mu (GSTMI) puede reducir la capacidad de las células para desintoxicar los agentes cancerígenos. Compruebe si existe una asociación entre la presencia o ausencia de polimorfismos GSTTl y GSTMl y cánceres de tiroides. Se trata de una revisión sistemática y metaanálisis, con selección de artículos científicos en las bases de datos: PubMed, SciELO, ScienceDirect y LILACS. Se extrajeron los datos de 15 artículos y las pruebas estadísticas, considerando un límite de significancia del $5 \%$, se realizaron con la ayuda del software STATA ${ }^{\circledR}$ 16.0. La ausencia del polimorfismo GSTMl señaló una asociación con el desarrollo de cánceres de tiroides sin segregación por tipo $(0 \mathrm{R}=1,15$; IC del 95\% = 1,01-1,32). Sin embargo, la presencia de polimorfismos GSTTl y GSTMl no se asoció cuando los cánceres de tiroides se estratificaron por tipos (papilar, folicular y papilar + folicular). La eliminación de GSTMI y GSTT1 reduce la defensa contra agentes cancerígenos. Sin embargo, los resultados del presente estudio señalaron la ausencia de una asociación entre la presencia de polimorfismos GSTTl y GSTMl y la aparición de tipos de cáncer de tiroides. Por otro lado, la ausencia de GSTMl se asoció con cánceres de tiroides, cuando no se estratificó por tipos.

Palabras clave: Polimorfismo Genético, Neoplasias de la Tiroides, Gutatión Transferasa, Estrés 0xidativo.
\end{abstract}

\section{INTRODUÇÃo}

0 câncer da tireoide é um distúrbio endócrino e pode ser classificado em: diferenciados (papilífero e folicular, incluindo células de Hurthle); não diferenciados (anaplásico); e medulares (CHMIELIK et al., 2017; IGLESIAS et al., 2017; NET0 et al., 2019). 0s carcinomas papilar, folicular e de células de Hurthle representam, aproximadamente, 95\% de todos os cânceres de tireoide (MANIAKAS et al., 2018). No Brasil, os cânceres papilar e folicular representam 93\% dos casos de câncer da tireoide (SALES; FEITOSA, 2016), e, de acordo com o Instituto Nacional de Câncer (INCA), o câncer da tireoide apresenta maior incidência no sexo feminino, com taxa ajustada igual a 8,13 casos por 100 mil habitantes (INCA, 2020). Trata-se de uma doença multifatorial e, dentre os fatores de risco, comumente relatados, incluem: a exposição à radiação ionizante, IMC, deficiência de iodo, má alimentação e fatores genéticos (KH0DAMORADI et al., 2018; SEIB; SOSA, 2019).

Em relação aos aspectos genéticos, as enzimas glutaionas-S-tranferase, produzidas por diversos genes, como GSTT1(theta) e GSTMI(mu), estão envolvidas no metabolismo de hormônio esteroide, na desintoxicação de vários xenobióticos e produtos do estresse oxidativo (LI et al., 2012; FAGIN et al., 2017). Apesar do mecanismo da carcinogênese da tireoide ainda não estar totalmente elucidado, pesquisas apontam que a transformação das células foliculares, da tireoide, derivadas da endoderme ou das células C, leva a tipos distintos de cânceres (FAGIN et al., 2016; TCHEANDJIEU et al., 2020), e que as deleções dos genes GSTT1 e GSTMI resultam em 
genótipos nulos e levam a um déficit geral na atividade enzimática, reduzindo a capacidade das células em desintoxicar agentes carcinogênicos, o que confere suscetibilidade à determinados cânceres (CHATTERJEE; GUPTA, 2018).

0 desequilíbrio entre oxidantes e antioxidantes estabelece o estresse oxidativo e, por consequência, as células se tornam vulneráveis às diversas espécies reativas e substâncias nocivas. Com isso, o risco de desenvolvimento de doenças é elevado e, dentre as possíveis doenças, se destaca o câncer, resultante de dano genético, ocasionado pelo estresse oxidativo. 0 perfil antioxidante é constituído por enzimas e nutrientes, com destaque para a glutationa peroxidase (GPx), catalase (CAT), superóxido dismutase (SOD) e glutationa-S-transferase (GST) (GONÇALVES et al., 2020; CHATTERJEE; GUPTA, 2018).

As glutationas-S-transferase (GST) são enzimas de grande importância, na desintoxicação de compostos endógenos e exógenos, como espécies reativas de oxigênio e de nitrogênio, bem como na desintoxicação de xenobióticos, como carcinógenos ambientais e drogas terapêuticas (DASARI et al., 2017; ZHANG et al., 2019). A GSTMI, GSTT1 e GSTP1 são as principais isoformas investigadas em estudos de associação genética, avaliando o risco de desenvolvimento de diversas doenças (MOGHIMI et al., 2019; CHATTERJEE; GUPTA, 2018). Com isso, o objetivo deste estudo foi verificar a associação entre a presença ou ausência dos polimorfismos GSTT1 e GSTMI com o câncer da tireoide e seus tipos, considerando as análises: todos os cânceres da tireoide; papilar; folicular; papilar + folicular.

\section{MATERIAL E MÉTODOS}

Trata-se de revisão sistemática e meta-análise de caráter descritivo e analítico. Foram selecionados artigos científicos nas bases de dados: PubMed, SciELO, ScienceDirect e LILACS. Para aspecto descritivo (revisão bibliográfica) foram consideradas as pesquisas publicadas nos últimos quatro anos (2016-2020), por outro lado, para revisão sistemática e meta-análise não houve limitação temporal. Foram considerados os operadores booleanos “AND” e "OR” e adotados os descritores: polimorfismo genético, neoplasias da glândula tireoide, glutationa-S-transferase e estresse oxidativo, definidos nos Descritores de Ciências da Saúde (DeCS).

Foram encontradas 2.302 referências e excluídas 2.270. Com a aplicação dos critérios de elegibilidade, 14 artigos foram incluídos nesta meta-análise (Figura 1). 


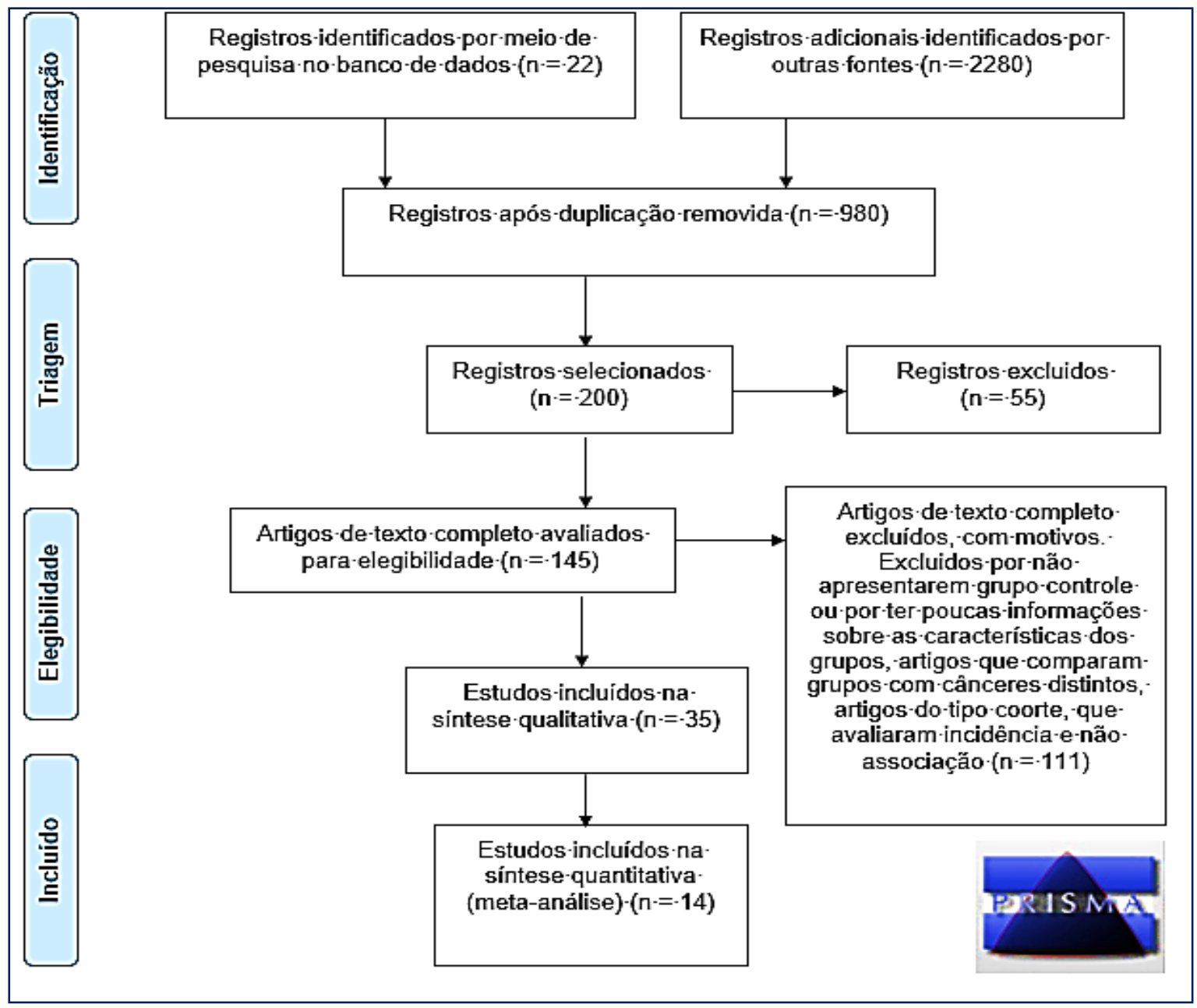

Figura 1. Fluxograma de seleção de pesquisas para aspecto descritivo e sistemática Fonte: Autores, 2020.

Os critérios para inclusão foram: artigos relacionados ao câncer da tireoide e que avaliaram o polimorfismo dos genes da glutationa-S-transferase, pesquisas do tipo casocontrole. Como critérios de exclusão, foram descartados: artigos que compararam os canceres da tireoide, artigos sem controle, artigos com dados duplicados, pesquisas do tipo coorte e pesquisas que não forneciam dados metodológicos suficientes para credibilidade dos resultados (metodologias que não descreveram as características dos grupos casos e controles) (Tabela 1).

Adicionalmente, foram considerados artigos publicados nos idiomas: inglês, português e espanhol. A avaliação, extração e tabulação de dados basearam-se nas instruções e recomendações PRISMA (Preferred Reporting Items for Systematic Reviews and Meta-Analyses) (MOHER et al., 2009). Com isso, os artigos selecionados, para a extração de dados, foram submetidos à avaliação de dois revisores e não houve discordâncias quanto as interpretações. Os dados tabulados, na análise qualitativa, foram caracterizados como dicotômicos, isto é, pesquisas que trabalharam com duas possíveis variáveis. Desta forma, os dados, referentes ao 
polimorfismo (presença e ausência) dos genes GSTMI e GSTTI, em indivíduos com câncer de tireoide, considerando os tipos: papilar, folicular, papilar + folicular e todos os cânceres (caso) e indivíduos saudáveis (controle), foram extraídos e tabulados em planilha Microsoft ${ }^{\circledR}$ Excel 2013 (Tabela 2).

Posteriormente, foi realizado o teste estatístico do qui-quadrado $\left(\chi^{2}\right)$ de heterogeneidade, com objetivo de verificar se os estudos apresentam resultados semelhantes. Quando a heterogeneidade não foi significativa $(p>0,05)$, utilizou-se 0 teste de efeito fixo Mantel-Haenszel; por outro lado, quando foi significante $(p<0,05)$, foi utilizado o teste de efeito randomizado DerSimonian-Laird. Da mesma forma, quando o teste $\mathrm{I}^{2}$ apresentou resultado $\geq 50 \%$, o efeito randomizado foi aplicado (HIGGINS et al., 2003; HIGGINS; THOMPSON, 2002). Para significância dos resultados, foi considerado o alfa igual a 5\% (p-valor<0,05). 0s testes estatísticos foram realizados com o auxílio do software STATA ${ }^{\circledR} 16.0$.

\section{RESULTADOS E DISCUSSÃO}

Para o polimorfismo GSTMI, foram avaliados 3.932 indivíduos, divididos em pacientes com câncer de tireoide ou grupo caso $(n=1.490)$ com frequência de eventos igual a 45,84\% (presença do polimorfismo), e pacientes sem câncer de tireoide, grupo controle ( $n=2.442)$ com $51,1 \%$ de eventos. 0 s dados foram estratificados por tipo de câncer de tireoide, em: papilar ( $n=2.395)$ com 46,1\% de eventos e controle ( $n=3.609)$ com 47,8\% de eventos; folicular $(n=160)$ com $51,8 \%$ de eventos e controle ( $n=1.181)$ com 53\% de eventos, papilar + folicular ( $n=396)$ com 52,27\% de eventos e controle ( $n=876$ ) com 48,28\% de eventos. Para o polimorfismo GSTTI, foram avaliados 3.782 indivíduos, divididos em pacientes com câncer de tireoide (n=1.416) com 77,89\% de eventos, grupo caso, e pacientes sem câncer de tireoide (n=2.366) com 77,09\% de eventos, grupo controle. Os dados foram estratificados por tipo de câncer de tireoide, em: papilar $(n=2.379)$ com 59,39\% de eventos e controle ( $n=3.609)$ com $65 \%$ de eventos; folicular ( $n=155)$ com $78,7 \%$ de eventos e controle ( $n=1.181)$ com 79,17\% de eventos; papilar + folicular ( $n=396)$ com $77,27 \%$ de eventos e controle ( $n=876)$ com $78,99 \%$ de eventos (Tabela 2$)$. 
Tabela 1. Dados qualitativos de todos os artigos selecionados para a presente meta-análise, 2020

\begin{tabular}{|c|c|c|c|c|c|c|c|}
\hline Autor, Ano & Controles aleatórios & Caso-controle & País & Média de Idade (anos) & Gênero feminino (f) / masculino (m) & Etnia & Técnica \\
\hline GASPAR et al. (2004) & Sem informação & Sim & Portugal & 53 & $86 \mathrm{f} / 17 \mathrm{~m}$ & $\begin{array}{l}\text { Caucásica } \\
\text { Sem }\end{array}$ & PCR \\
\hline HERNÁNDEZ et al. (2003) & Sem informação & Sim & Espanha & 44,81 & $97 \mathrm{f} / 34 \mathrm{~m}$ & $\begin{array}{l}\text { informação } \\
\text { Sem }\end{array}$ & PCR \\
\hline CANBAY et al. (2003) & Sim & Sim & Turquia & 41,5 & $26 \mathrm{f} / 6 \mathrm{~m}$ & informação & PCR \\
\hline REIS et al. (2010) & Sim & Sim & Brasil & $18-83$ anos & $102 \mathrm{f} / 19 \mathrm{~m}$ & Diversos & PCR \\
\hline HERNÁNDEZ et al. (2008) & Sem informação & Sim & Espanha & 45,9 & $127 \mathrm{f} / 49 \mathrm{~m}$ & Caucásica & PCR \\
\hline TCHEANDJIEU et al. (2020) & Sim & Sim & França & 51,3 & $402 \mathrm{f} / 102 \mathrm{~m}$ & Diversos & PCR \\
\hline BUFAL0 et al. (2006) & Sem informação & Sim & Brasil & 46 & $191 f / 57 \mathrm{~m}$ & Diversos & PCR \\
\hline SAMPAI0 (2007) & Sem informação & Sim & Brasil & $16-81$ & $149 \mathrm{f} / 25 \mathrm{f}$ & Diversos & PCR \\
\hline MORARI et al. (2002) & Sem informação & Sim & Brasil & Sem informação específica & Sem informação específica & Diversos & PCR \\
\hline SIRAJ et al. (2008) & Sim & Sim & Arábia Saudita & Sem informação específica & 223 & $\begin{array}{l}\text { Sem } \\
\text { informação } \\
\text { Sem }\end{array}$ & PCR \\
\hline KWE0N et al. (2014) & Sim & Sim & Coréia do Sul & Sem informação específica & $1790 \mathrm{f} / 404 \mathrm{~m}$ & informação & PCR \\
\hline LEMOS et al. (2008) & Sem informação & Sim & Portugal & 44,5 & $149 \mathrm{f} / 39 \mathrm{~m}$ & Caucásica & PCR \\
\hline GUILHEN et al. (2009) & Sem informação & Sim & Brasil & 41,77 & 195 & Diversos & PCR \\
\hline H0 et al. (2006) & Sem informação & Sim & Estados Unidos & 45,6 & $130 \mathrm{f} / 71 \mathrm{~m}$ & Diversos & PCR \\
\hline
\end{tabular}

Fonte: Autores, 2020.

Tabela 2. Dados quantitativos de todos os artigos selecionados para a presente meta-análise, 2020

Revista Internacional de Ciências, v. 11, n. 01, p. 261-275, mai-ago, 2021 


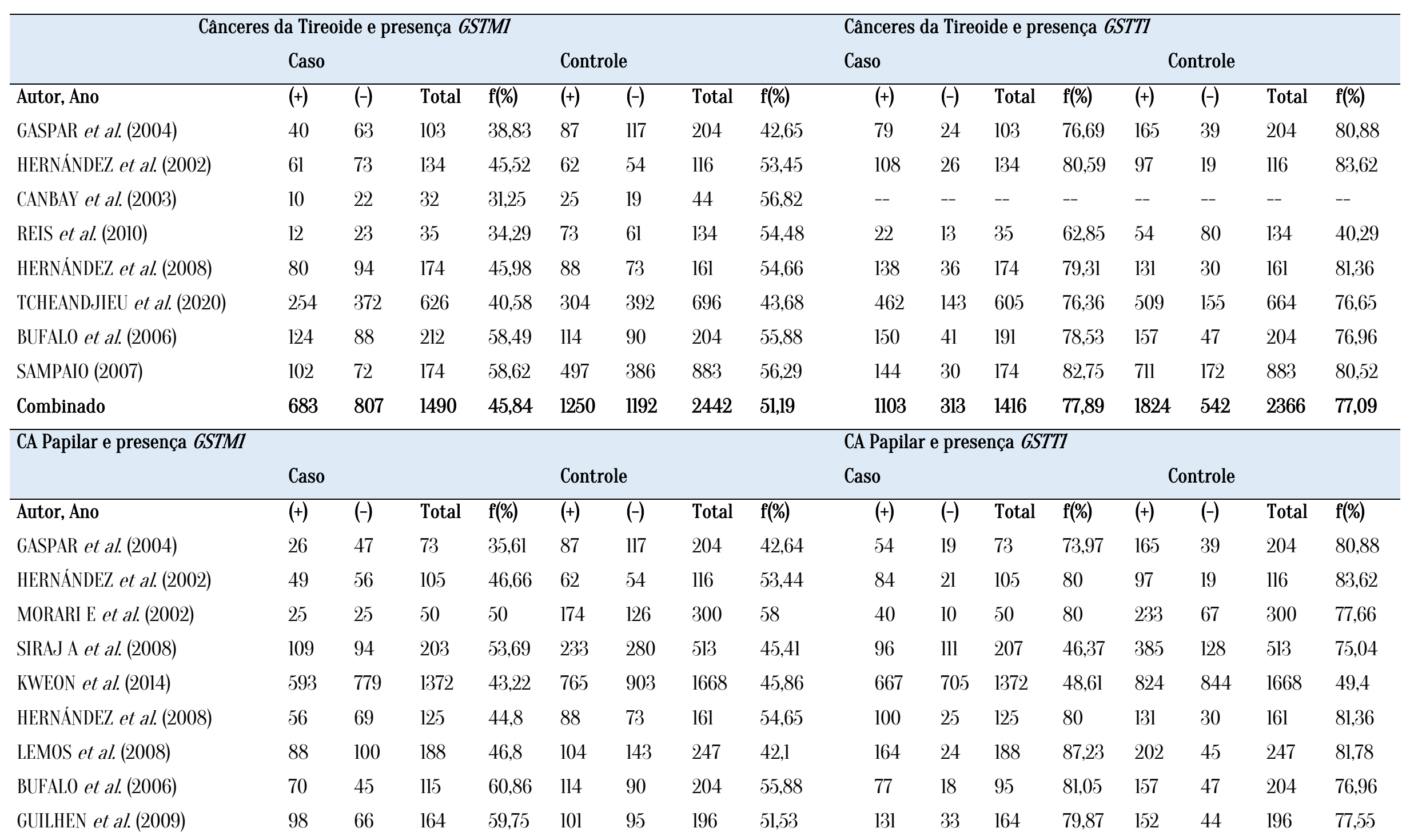

Revista Internacional de Ciências, v. 11, n. 01, p. 261-275, mai-ago, 2021 


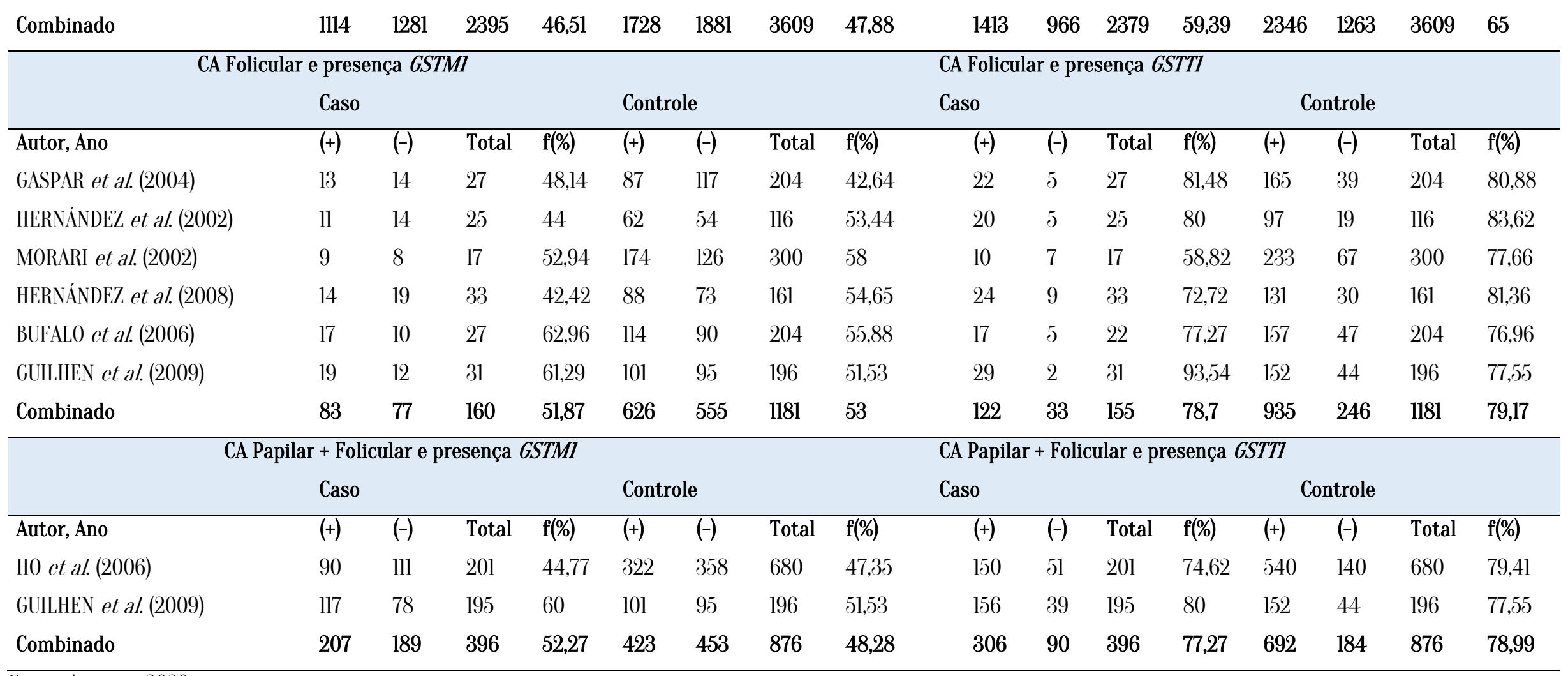

Fonte: Autores, 2020. 
Quando considerado todos os cânceres da tireoide, a presença do polimorfismo GSTMI resultou em Odds Ratio (OR) de 0,87 (IC95\%=0,76-0,99; $\left.\chi^{2}=11,53 p=0,12 ; I^{2}=39 \%\right)$, e, para GSTTI, OR de 1,03 (IC95\%=0,87-1,21; $\left.\chi^{2}=7,40 \quad p=0,29 ; \quad I^{2}=19 \%\right)$. A presença do polimorfismo GSTT1 não apresentou relação com todos os cânceres da tireoide, por outro lado, o polimorfismo GSTMI apresentou-se, proporcionalmente, superior no grupo sem câncer, apontando que o polimorfismo, quando presente, é fator genético de proteção contra todos os cânceres da tireoide. A ausência do polimorfismo GSTMl apontou risco aumentado de desenvolver todos os cânceres da tireoide com 0R=1,15 (IC95\%=1,01-1,32), ou seja, o risco do desenvolvimento em indivíduos com ausência de GSTMl é maior que em indivíduos com a presença. A heterogeneidade sem significância em ambas as análises, justifica 0 efeito fixo (Figura 2).

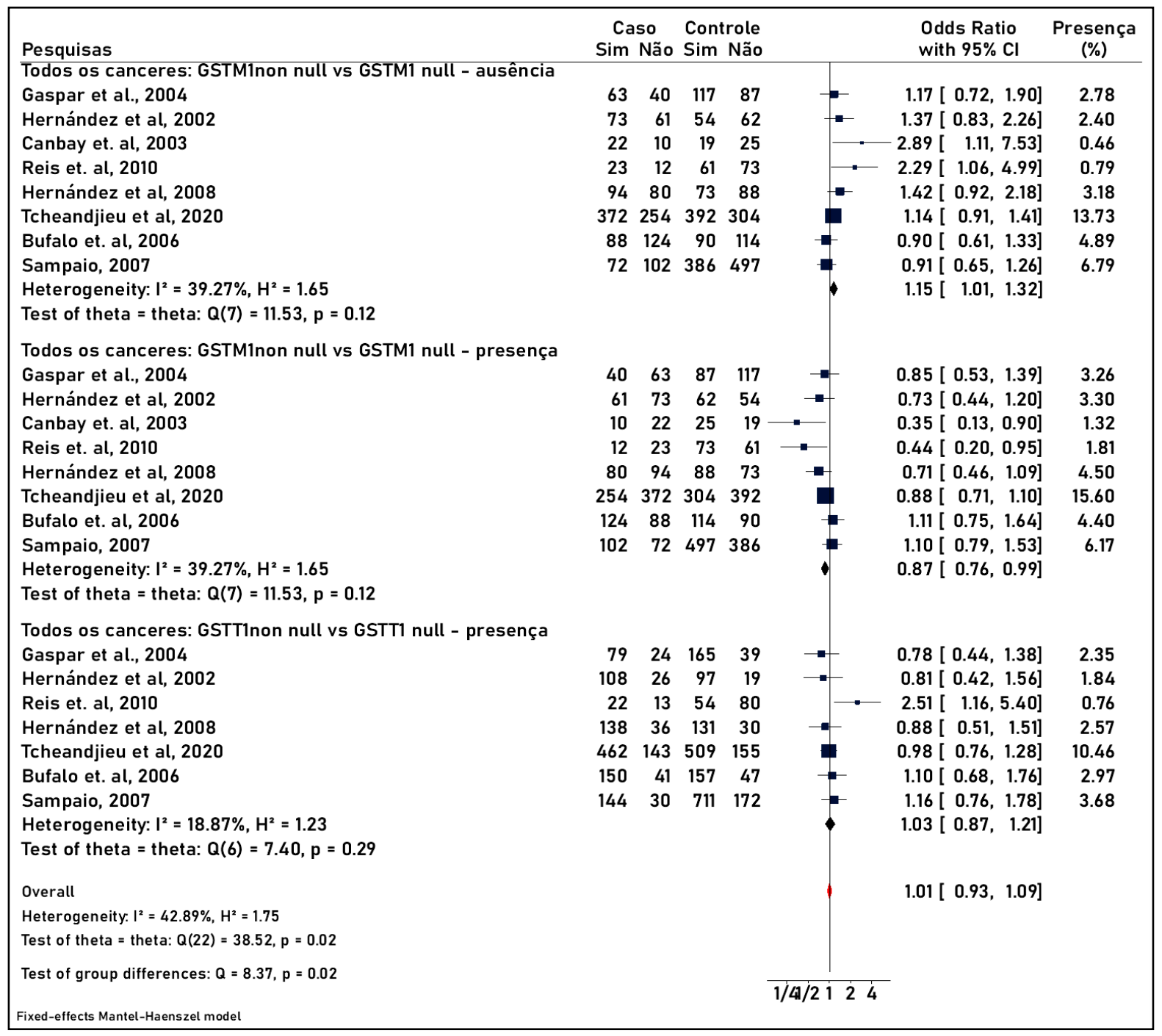

Figura 2. Gráficos referentes às associações dos polimorfismos GSTMI e GSTT1 com todos os cânceres da tireoide.

Fonte: Autores, 2020. 
Os polimorfismos GSTMl e GSTT1 não apresentaram associação com os cânceres papilar e folicular, quando analisados isolados. A comparação do grupo sem câncer com o grupo com câncer papilar, apresentou para GSTMI0R=1,00 (IC95\%=0,83-1,20; $\left.\chi^{2}=15,92 p=0,04 ; I^{2}=50 \%\right)$ e para GSTT1 0R=0,87 (IC95\%=0,60-1,27; $\left.\chi^{2}=51,45 p<0,00001 ; I^{2}=84 \%\right)$. A heterogeneidade significante entre os resultados das pesquisas plotadas, contrastou com o efeito randomizado utilizado nas duas análises estatísticas. A heterogeneidade reflete a diferença do número de participantes entre as pesquisas, descartando a exploração por etnia, uma vez que a maioria das pesquisas que apresentaram resultados distintos provieram dos mesmos países e utilizaram as mesmas técnicas, com diferença apenas no tamanho amostral (Figura 3).

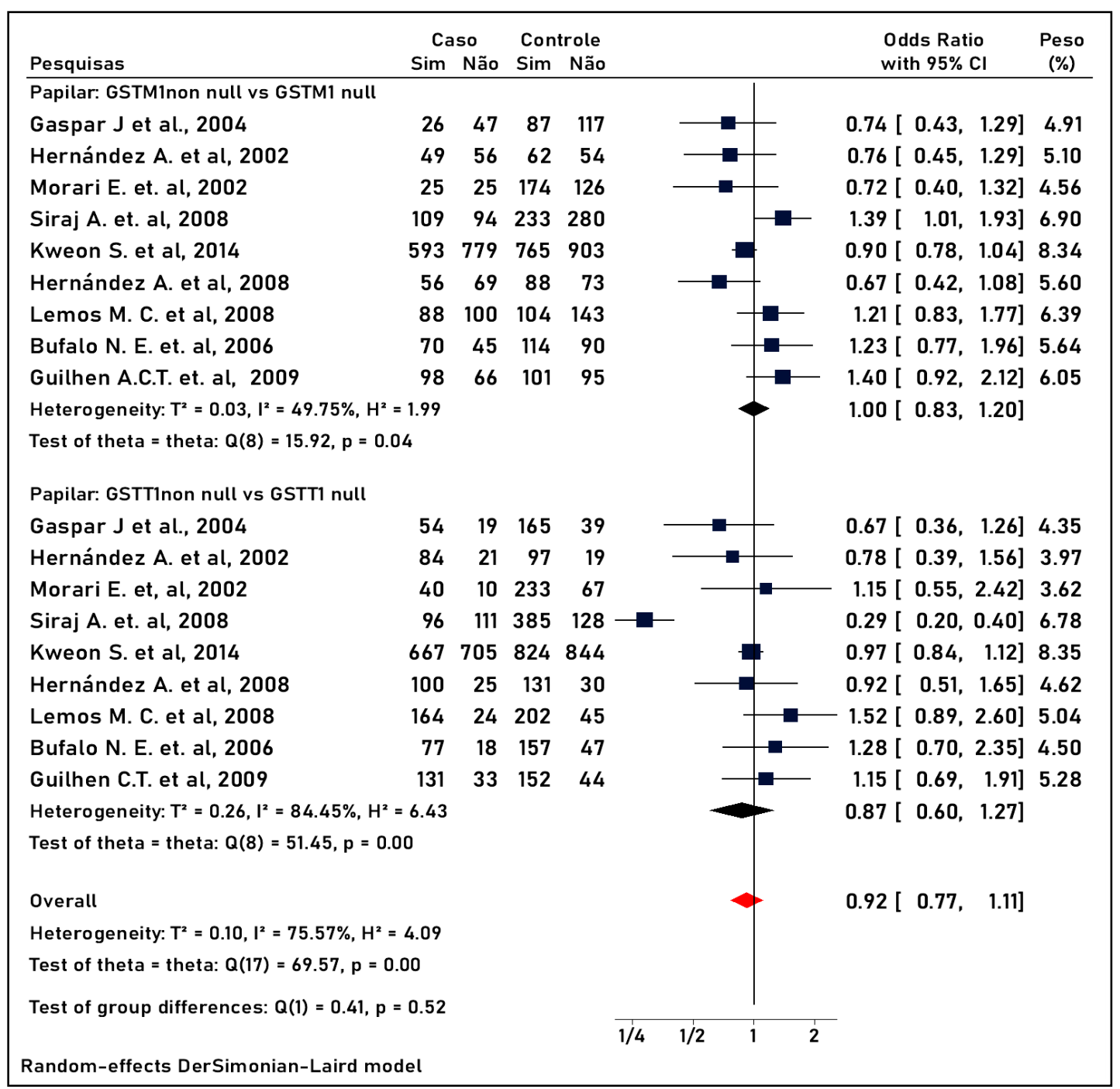

Figura 3. Gráficos referentes às associações dos polimorfismos GSTMl e GSTT1 e câncer papilar da tireoide.

Fonte: Autores (2020).

Sem diferença significante entre grupos caso e controle, os polimorfismos GSTM1e GSTT1 não apresentaram associação com o câncer folicular da tireoide. Por meio da combinação de 
seis pesquisas, a presença dos polimorfismos GSTMI e GSTT1 resultaram, respectivamente, em OR=0,99 (IC95\%=0,71-1,38; I²=16,09\%) e 0R=0,93 (IC95\%=0,61-1,40; $\left.I^{2}=34,61 \%\right)$, ambas análises sem heterogeneidade significante. Da mesma forma, quando analisados os dados referentes a indivíduos portadores dos cânceres papilar + folicular, os resultados não apontaram associação com a presença dos polimorfismos: $\operatorname{GSTMI}\left(0 \mathrm{R}=1,07 ; \mathrm{IC} 95 \%=0,84-1,37 ; \mathrm{I}^{2}=66,21 \%\right)$ e $\operatorname{GSTT7}(0 \mathrm{R}=0,89$; IC95\% = 0,66-1,20; $I^{2}=44,65 \%$ ) (Figura 4).

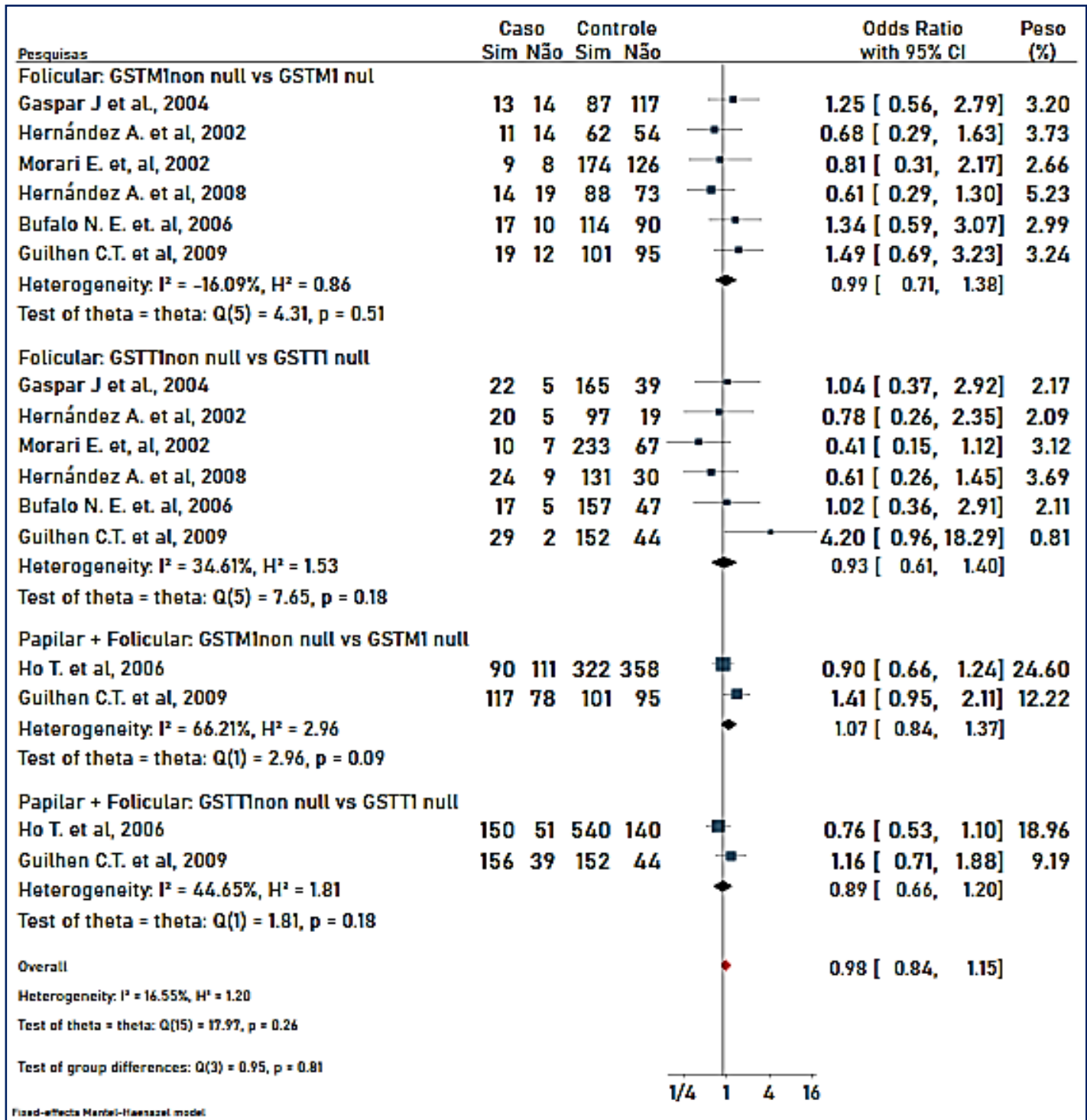

Figura 4. Gráficos referentes às associações dos polimorfismos GSTMle GSTT7 e câncer folicular da tireoide e associação dos polimorfismos GSTMI e GSTT1 e cânceres papilar + folicular da tireoide.

Fonte: Autores (2020).

Segundo Khodamoradi et al. (2018), o desenvolvimento de câncer de tireoide é influenciado por: fatores ambientais, estilo de vida, fatores étnicos e geográficos. Com isso, a heterogeneidade entre os resultados das pesquisas, pode ser explicado por diferenças entre as características populacionais. Em relação ao fator genético, destacam-se os polimorfismos. 0s 
cromossomos homólogos são bastante similares, mas em determinadas localizações do cromossomo (loci) pode haver variabilidade na sequência do DNA. Com isso, a variação com frequência superior a 1\% da população, denomina-se polimorfismo (ROCHA et al., 2007).

De acordo com Tcheandjieu et al. (2020), entre os genes envolvidos na atividade da glândula da tireoide, estão os polimorfismos da glutationa-S-transferase (GST), como GSTMl e GSTTI. As enzimas codificadas por estes genes atuam no metabolismo do hormônio esteroide e na desintoxicação de vários xenobióticos e produtos do estresse oxidativo. Desta forma, a nulidade destes genes aumenta a vulnerabilidade à exposição a carcinógenos, promovendo a evolução da neoplasia (MILOŠEVIĆ-DJORDJEVIĆ et al., 2017).

A pesquisa de Milosevic-Djordjevic et al. (2020) apontou risco elevado de câncer de tireoide em indivíduos com ausência dos genes GSTMl e GSTTI, com índice de massa corporal (IMC) ou consumo de álcool.

Apesar das importantes funções da GST, pesquisas envolvendo participantes, com os variados tipos de cânceres da tireoide, não encontraram relação com a presença ou ausência dos genes GSTMI e GSTTI(HERNANDEZ et al., 2003; HERNANDEZ et al., 2008; TCHEANDJIEU et al., 2020). Isto pode ser observado nos gráficos forest plot, onde as pesquisas plotadas, com exceção do polimorfismo GSTMI, para todos os cânceres da tireoide, apresentam resultados sem significância estatística, ou seja, a presença ou ausência dos genes são proporcionalmente semelhantes quando comparados indivíduos saudáveis com indivíduos com câncer de tireoide (TCHEANDJIEU et al., 2020).

A presença do polimorfismo GSTMl, para todos os cânceres de tireoide, apontou proporcionalmente superior no grupo de indivíduos saudáveis, com isso, a avaliação da ausência do polimorfismo, comparando os grupos caso e controle, determinou relação entre a ausência de GSTMl e o desenvolvimento de todos os cânceres da tireoide. A Odds Ratio referente à ausência de GSTMI, encontrada nesta meta-análise, foi semelhante a OR isolada de Tcheandjieu et al. (2020), pesquisa plotada de maior peso, apontando assertividade no resultado obtido.

Os resultados desta meta-análise são de grande relevância científica, pois o número amostral, após a combinação de pesquisas, determina assertividade superior quando comparado às pesquisas originais, ou seja, os resultados, após combinação, têm maior representatividade populacional, não descartando a necessidade de pesquisas com maior número amostral, considerando os diversos fatores de risco característicos de cada população. De acordo com Milosevic-Djordjevic et al. (2020), disparidades na frequência de deleção de GSTMIe GSTTI, entre 
populações, em todo o mundo, podem explicar, parcialmente, as diferenças na incidência de câncer de tireoide.

\section{CONCLUSÃ0}

A meta-análise apontou associação entre ausência do polimorfismo GSTMl e cânceres da tireoide, considerando os dados sem segregação por tipo de câncer. Porém, não foi observada associação entre a presença dos polimorfismos GSTTle GSTMle os cânceres de tireoide do tipo papilar e folicular. Neste contexto, a realização de novos estudos sobre a temática é imprescindível, tendo em vista a amplitude de fatores, como os genéticos e ambientais, que podem influenciar na suscetibilidade dos indivíduos em desenvolver estes tipos de cânceres, bem como a importância da temática em questão. Além disso, o estabelecimento de uma maior amostra populacional torna-se necessário frente a confirmação da associação ou não do polimorfismo com o câncer de tireoide.

\section{AGRADECIMENTOS}

A introdução, o desenvolvimento e a conclusão receberam a contribuição de todos os autores presentes no trabalho, a metodologia foi realizada pelo autor Lucas Cândido Gonçalves e complementado pelo Joaquim Ferreira Fernandes e Bárbara Custódio Rodrigues da Silva. Os resultados foram redigidos por todos os autores. As referências, o resumo, o resumen e 0 abstract foram organizados pela Talita Ferreira Duarte, Thainá Ferreira Silva, Aline Ferreira da Silva Santos e Larissa de Oliveira Rosa Marques. Todos os aspectos descritivos foram revisados por todos os autores do estudo. A parte estatística foi desenvolvida pelo Lucas Cândido Gonçalves e corrigida pelo Antonio Márcio Teodoro Cordeiro Silva, que também participou como orientador e revisor descritivo do trabalho.

\section{REFERÊNCIAS BIBLIOGRÁFICAS}

BUFALO, N. E. et al. Smoking and susceptibility to thyroid cancer: an inverse association with CYPlAl allelic variants. Endocrine-Related Cancer, v. 13, n. 4, p. 1185-1193, 2006.

CANBAY, E. et al. Higher glutathione transferase in young thyroid carcinoma patients. Current Medical Research and Opinion, v. 19, n. 2, p. 102-106, 2003.

CHATTERJEE, A; GUPTA, S. The multifaceted role of glutathione S-transferases in cancer. Cancer Letters, v. 433, n. 2018, p. 33-42, 2018. 
CHMIELIK, E. et al. Heterogeneity of Thyroid Cancer. Pathobiology, v. 85, n. 1-2, p. 117-129, 2018.

FAGIN, J. A. et al. Biologic and clinical perspectives on thyroid cancer. New England Journal of Medicine, v. 375, n. 11, p. 1054-1067, 2016.

FAGIN, S. et al. Glutathione S-transferases detoxify endogenous and exogenous toxic agents-minireview. J Dairy Vet Anim Res, v. 5, n. 5, p. 00154, 2017.

GASPAR, J. et al. Combined effects of glutathione S-transferase polymorphisms and thyroid cancer risk. Cancer Genetics and Cytogenetics, v. 151, n. 1, p. 60-67, 2004.

GONCALVES, L. C. et al. Nutritional and enzymatic comparison between healthy and phenylketonuria individuals: systematic review and meta-analysis. Electronic Journal Collection Health, v. sn, n. 41, p. 1-11, 2020.

GUILHEN, A. C. T. et al. Cancer Prevention and Susceptibility Role of the N -Acetyltransferase 2 Detoxification System in Thyroid Cancer Susceptibility. Clinical Cancer Research, v. 15, n. 1, p. 406-413, 2009.

HERNANDEZ, A. et al. Glutathione S -transferase polymorphisms in thyroid cancer patients. Cancer Letters, v. 190, n. 1, p. 37-44, 2003.

HERNANDEZ, A. et al. Role of GST and NAT2 polymorphisms in thyroid cancer. Journal of Endocrinological Investigation, v. 31, n. 11, p. 1025-1031, 2008.

HIGGINS, J. P. T. et al. Measuring inconsistency in meta-analyses. Educ debate. v. 327, n. s/n, p. 557-560, 2003.

HIGGINS, J. P. T; THOMPSON, S.G. Quantifying heterogeneity in a meta-analysis. Stat Med. v. 21, n. s/n, p. 1539-1558, 2002.

H0, T. et al. Glutathione S-Transferase Polymorphisms and Risk of Differentiated Thyroid Carcinomas. Archives of otolaryngology - Head \& Neck Surgery, v. 132, n. 7, p. 756-761, 2006.

IGLESIAS, M. L. et al. Radiation exposure and thyroid cancer: a review. Archives of endocrinology and metabolism, v. 61, n. 2 , p. 180-187, 2017.

INCA. Brasil - Estimativa dos casos novos. INCA, 2020. Disponível em: <https://www.inca.gov.br/estimativa/estadocapital/brasil $\_$.

KHODAMORADI, F. et al. Incidence, Mortality, and Risk Factors of Thyroid Cancer in the World: A Review. World Cancer Research Journal, v. 5, n. 2, p. 9, 2018.

KWEON, S. et al. Polymorphisms of methylenetetrahydrofolate reductase and glutathione S -transferase are not associated with the risk of papillary thyroid cancer in Korean population. Molecular Biology Reports, 2014.

LEMOS, M. C. et al. Combined GSTM1 and GSTT1 null genotypes are associated with a lower risk of papillary thyroid cancer. Journal of Endocrinological Investigation, v. 31, n. 6, p. 542-545, 2008.

LI, J. et al. Glutathione S-transferase M1, T1, and Pl polymorphisms and thyroid cancer risk: A meta-analysis. Cancer Epidemiology, v. 36, n. 6, p. e333-e340, 2012.

MANIAKAS, A.; DAVIES, L.; ZAFERE0, M. E. Thyroid disease around the world. Otolaryngologic Clinics of North America, v. 51, n. 3, p. 631-642, 2018.

MILOŠEVIĆ-DJORDJEVIĆ, 0. et al. Influence of GSTTl and GSTMl null genotypes on differentiated thyroid cancer risk and baseline and radioiodine induced cytogenetic damage in peripheral blood lymphocytes of patients. Genetika, 2017.

MOGHIMI, M. et al. Association of GSTM1, GSTT1, GSTM3, and GSTP1 genes polymorphisms with susceptibility to osteosarcoma: a case-control study and meta-analysis. Asian Pacific Journal of Cancer Prevention: APJCP, v. 20 , n. 3, p. 675, 2019. 
MOHER, D. et al. Group TP. Preferred Reporting Items for Systematic Reviews and Meta-Analyses: The PRISMA Statement. Plos Med, v. 6. n. 7, p. 1-7, 2009.

MORARI, E. C. et al. The Null Genotype of Glutathione S-Transferase Ml and Tl Locus Increases the Risk for Thyroid Cancer. Cancer Epidemiology, Biomarkers \& Prevention, v. 11, n. 11, p. 1485-1488, 2002.

NET0, B. C. B. et al. Incidência do câncer de tireoide na população brasileira, 2006-2015. Antonio Carlos Weston, v. 63, n. 3, p. 307-312, 2019.

REIS, A. A. S. et al. Involvement of CYPIAl, GST, 72TP53 polymorphisms in the pathogenesis of thyroid nodules. Genetics and Molecular Research, v. 9, n. 4, p. 2222-2229, 2010.

ROCHA, A. P. et al. Polimorfismos genéticos: implicações na patogênese do carcinoma medular de tireóide. Arq Bras Endocrinol Metab, São Paulo, v. 51, n. 5, p. 723-730, July 2007.

SALES, D. F.; FEITOSA, C. A. The distribution and evolution of indicators of hospital morbidity and mortality for thyroid cancer in Brazil. Brazilian Journal of Medicine and Human Health, v. 4, n. 4, 2016.

SAMPAI0, A. C. Impacto do perfil alimentar e genotípico do sistema glutationa S- transferase na susceptibilidade ao câncer. 2007. Dissertação (Mestrado) - Faculdade de Ciências Médicas, Universidade Estadual de Campinas, Campinas, 2007.

SEIB, C. D; SOSA, J. A. Evolving Understanding of the Epidemiology of Thyroid Cancer. Endocrinol Metab Clin North Am, v. 48, n. 1, p. 23-35, 2019.

SIRAJ, A. K. et al. Polymorphisms of selected Xenobiotic Genes contribute to the development of Papillary Thyroid Cancer susceptibility in Middle Eastern population. BMC Medical Genetics, v. 9, n. 1, p. 61, 2008.

TCHEANDJIEU, C. et al. Role of GSTMl and GSTTl genotypes in differentiated thyroid cancer and interaction with lifestyle factors: Results from case-control studies in France and New Caledonia. PLoS ONE, v. 15, n. 1, p. e0228187, 2020 .

ZHANG, Y. et al. Glutathione S-transferase gene polymorphisms and risk of nasal or colorectal polyposis. Bioscience Reports, v. 39, n. 1, p. BSR20181226, 2019. 